University of Vermont

UVM ScholarWorks

Rubenstein School of Environment and Natural Rubenstein School of Environment and Natural Resources Faculty Publications

$1-1-2012$

\title{
Carbon storage, timber production, and biodiversity: Comparing ecosystem services with multi-criteria decision analysis
}

\author{
W. Scott Schwenk \\ University of Vermont \\ Therese M. Donovan \\ University of Vermont \\ William S. Keeton \\ University of Vermont \\ Jared S. Nunery \\ University of Vermont
}

Follow this and additional works at: https://scholarworks.uvm.edu/rsfac

Part of the Agriculture Commons, Climate Commons, and the Sustainability Commons

\section{Recommended Citation}

Schwenk WS, Donovan TM, Keeton WS, Nunery JS. Carbon storage, timber production, and biodiversity: comparing ecosystem services with multi-criteria decision analysis. Ecological Applications. 2012 Jul;22(5):1612-27.

This Article is brought to you for free and open access by the Rubenstein School of Environment and Natural Resources at UVM ScholarWorks. It has been accepted for inclusion in Rubenstein School of Environment and Natural Resources Faculty Publications by an authorized administrator of UVM ScholarWorks. For more information, please contact scholarworks@uvm.edu. 


\title{
Carbon storage, timber production, and biodiversity: comparing ecosystem services with multi-criteria decision analysis
}

\author{
W. Scott Schwenk, ${ }^{1,4}$ Therese M. Donovan, ${ }^{2}$ William S. Keeton, ${ }^{3}$ and Jared S. Nunery ${ }^{3,5}$ \\ ${ }^{1}$ Vermont Cooperative Fish and Wildlife Research Unit, University of Vermont, Burlington, Vermont 05405 USA \\ ${ }^{2}$ U.S. Geological Survey, Vermont Cooperative Fish and Wildlife Research Unit, University of Vermont, \\ Burlington, Vermont 05405 USA \\ ${ }^{3}$ Rubenstein School of Environment and Natural Resources, University of Vermont, Burlington, Vermont 05405 USA
}

\begin{abstract}
Increasingly, land managers seek ways to manage forests for multiple ecosystem services and functions, yet considerable challenges exist in comparing disparate services and balancing trade-offs among them. We applied multi-criteria decision analysis (MCDA) and forest simulation models to simultaneously consider three objectives: (1) storing carbon, (2) producing timber and wood products, and (3) sustaining biodiversity. We used the Forest Vegetation Simulator (FVS) applied to 42 northern hardwood sites to simulate forest development over 100 years and to estimate carbon storage and timber production. We estimated biodiversity implications with occupancy models for 51 terrestrial bird species that were linked to FVS outputs. We simulated four alternative management prescriptions that spanned a range of harvesting intensities and forest structure retention. We found that silvicultural approaches emphasizing less frequent harvesting and greater structural retention could be expected to achieve the greatest net carbon storage but also produce less timber. More intensive prescriptions would enhance biodiversity because positive responses of early successional species exceeded negative responses of late successional species within the heavily forested study area. The combinations of weights assigned to objectives had a large influence on which prescriptions were scored as optimal. Overall, we found that a diversity of silvicultural approaches is likely to be preferable to any single approach, emphasizing the need for landscape-scale management to provide a full range of ecosystem goods and services. Our analytical framework that combined MCDA with forest simulation modeling was a powerful tool in understanding trade-offs among management objectives and how they can be simultaneously accommodated.
\end{abstract}

Key words: biodiversity; carbon sequestration and storage; forest ecosystem modeling; forest planning; multi-criteria analysis; multi-objective forest management; northern hardwood forests (USA); timber production.

\section{INTRODUCTION}

Growing concerns about global climate change and loss of biodiversity have intensified efforts to manage forests for multiple ecosystem services and functions. One critical function of forests is that they serve as large reservoirs of carbon within the global carbon cycle (Houghton 2007). How forests are managed can significantly affect whether they act as net carbon sources or sinks (Birdsey et al. 2006), and therefore forest management practices can play an important role in lessening the intensity of global climate change induced by rising atmospheric $\mathrm{CO}_{2}$ concentrations. Additionally, forests provide a diversity of important

Manuscript received 12 May 2011; revised 3 January 2012; accepted 23 January 2012. Corresponding Editor: J. M. Marzluff.

${ }^{4}$ Present address: North Atlantic Landscape Conservation Cooperative, 300 Westgate Center Drive, Hadley, Massachusetts 01035 USA. E-mail: w.scott.schwenk@gmail.com

${ }^{5}$ Present address: Rainforest Alliance, 65 Millet Street, Richmond, Vermont 05477 USA. ecosystem goods and services, including timber. Not only do revenues from wood products provide substantial direct economic benefits, they can act as powerful incentives to sustain forests, habitats, and undeveloped space over the long term (Fischer et al. 2006, Ruddell et al. 2007). Moreover, forests support a large proportion of the world's terrestrial species (Lindenmayer and Franklin 2002). Forest biodiversity provides humans with important food sources, recreational and aesthetic opportunities, and other benefits (Ehrlich and Ehrlich 1992, Daily et al. 1997).

Forest management practices vary greatly in their effects on carbon storage and temporal dynamics (Nunery and Keeton 2010), timber production, and provision of habitats for biodiversity (Lindenmayer and Franklin 2002). Challenges arise in managing these multiple ecosystem services because of trade-offs among the mix of services provided by a given management practice. A practice that maximizes one objective, such as timber production, is unlikely to simultaneously maximize all other ecosystem services. An additional challenge is quantifying the value of both market and 
nonmarket goods and services provided by forests (Farley 2008), which may be expressed in disparate units that are not readily compared.

One approach for evaluating forest management alternatives is multi-criteria decision analysis (MCDA; also known as multiple criteria decision support, among other names). MCDA is a collection of formal methods used to select a justifiable course of action that explicitly accounts for multiple, conflicting objectives (Belton and Stewart 2002, Mendoza and Martins 2006). One procedure for MCDA is to begin by specifying management objectives and to weight the objectives based on value judgments (Fig. 1). For instance, in the simple case of deciding which management option to implement at a single site, a forest manager may value carbon storage, timber income, and biodiversity equally (with resulting weights of 0.333 for each objective), or may value one objective at twice the level of the others (with resulting weights of $0.50,0.25$, and 0.25 ). Given a set of standardized metrics and weights for each objective, a management prescription is assigned to the site and the expected effects of the chosen prescription are quantified. The quantities for the objectives are known as the "partial utilities" of a management decision and are then summed to yield the total utility of a management decision (Fig. 1). By repeating this process for other potential management prescriptions, the prescription that maximizes total utility can be identified and applied.

MCDA also allows a structured decision analysis for cases where different forest management prescriptions can be applied to different stands or compartments to maximize the total utility across compartments. In this case, a "portfolio" defines the management prescription assigned to each compartment and the total utility is the sum of utilities across compartments. For instance, if 10 compartments are available for management, the total utility may be maximized by assigning prescription A to compartments $1,2,4,5,8$, and 9 and prescription $\mathrm{B}$ to compartments 3, 6, 7, and 10. In recent years, MCDA has been successfully applied to complex forest management scenarios (Kangas and Kangas 2005, DiazBalteiro and Romero 2008), although analyses to date have not combined the objectives of carbon storage and timber harvest with evaluation of an extensive set of species to represent biodiversity.

In this paper we apply MCDA to support an overall goal of managing forests for multiple ecological services and functions, as represented by three management objectives: (1) storing carbon, (2) producing wood products, and (3) sustaining biodiversity using a set of wildlife species (Fig. 1). We tested the analysis using a representative forest ecosystem in the northeastern United States for a set of specific metrics over a 100year time period based on the output of forest development simulation modeling. We considered four alternative forest management prescriptions that spanned a range of harvesting intensities and frequen- cies. Questions we investigated included the following: (1) To what extent can all three objectives be simultaneously accommodated, and what trade-offs are necessary? (2) How do different management prescriptions compare in their capacity to support individual objectives and the overall goal of multifunctional forest ecosystems? (3) What are the implications for management of forests across multiple sites or large areas?

\section{Methods}

\section{Study area, sites, and field sampling}

Our study investigated northern hardwood-conifer forests in the state of Vermont, USA, which is predominantly forested and in which Acer saccharum (sugar maple), Fagus grandifolia (American beech), Tsuga canadensis (eastern hemlock), and Betula alleghaniensis (yellow birch) form the major late-successional species. Within the study area, we measured breeding bird biodiversity and forest characteristics at 533 randomly located sites that were predominantly forested (including early successional forests); see Mitchell and Donovan (2008) for an overview of sampling procedures. Elevation of sites ranged from 29 to $877 \mathrm{~m}$ (mean $424 \mathrm{~m}$ ) and data were collected in 2003 or 2004. At each site, the species identity, diameter at breast height (dbh, $1.37 \mathrm{~m}$ height), and live/dead status were recorded for trees at least $2.54 \mathrm{~cm}$ in diameter selected in a variable radius plot with a metric 2.3-factor prism. Bird observations consisted of three single-observer 10minute point counts, separated by 2 -minute intervals, conducted at each site during the breeding season. All bird species observed within $75 \mathrm{~m}$ were recorded.

Our analysis involved simulating forest development responses to a range of possible management activities. From the 533 sites, which included a variety of forest types and successional stages, we chose a subset of 42 sites (Appendix A; see Plate 1) representative of mature northern hardwood composition (basal area $\geq 25 \mathrm{~m}^{2} /$ ha, quadratic mean diameter $\geq 20 \mathrm{~cm}$, and elevation $<600$ $\mathrm{m})$. These sites contained sufficient stocking to implement forest management at the commencement of forest simulation, which maximized the effect of management.

\section{Forest simulation model}

We used the Forest Vegetation Simulator (FVS) to simulate forest changes at each site over 100-year model runs in 5-year time steps and to estimate carbon (C) storage and timber production at each time step. FVS is a distance-independent, individual tree-based model of forest growth designed for even- and uneven-aged stands with simple- to mixed-species composition (Crookston and Dixon 2005). Although many forest vegetation simulation models are available, each with strengths and weaknesses (Wolfslehner and Seidl 2010), we chose FVS for its ability to simulate forest management activities and the availability of a model variant calibrated for northern hardwoods (Ray et al. 2009a). We used the Northeast Variant (NE-FVS), which uses growth and 


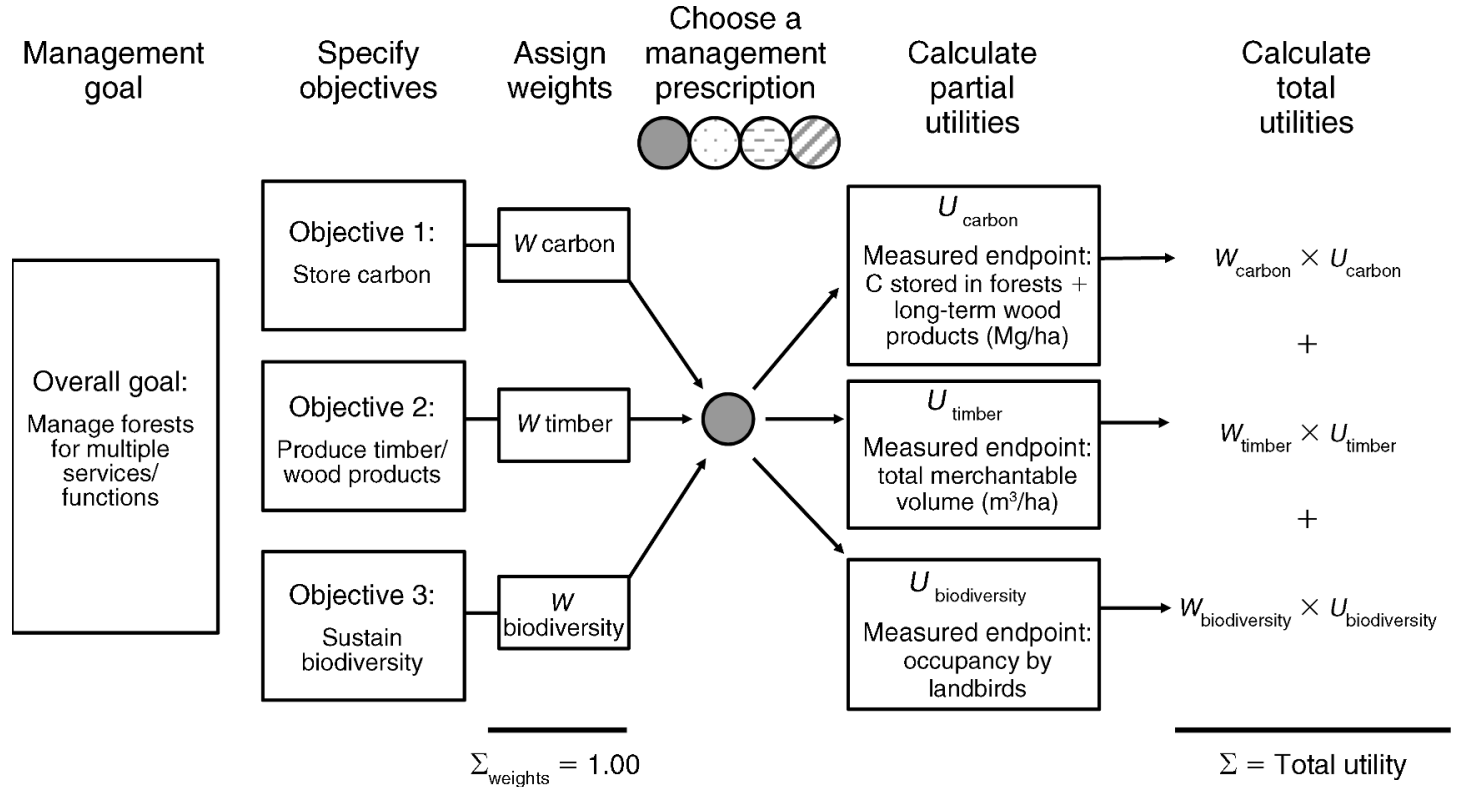

FIG. 1. Components of multi-criteria decision analysis (MCDA) including objectives, endpoints to measure the relative ability of management prescriptions to achieve the objectives, weights ( $W$, value preferences) for objectives, and calculation of total utility $(U)$ of a management prescription. In this study, carbon storage and timber production were estimated directly from outputs of 100 -year forest growth simulations under different management prescriptions. Forest bird occupancy was estimated using occupancy models for 51 landbird species linked to forest growth simulations. Partial utilities were calculated by rescaling measured endpoints between $0 \%$ and $100 \%$.

yield equations from NE-TWIGS (Hilt and Teck 1989) and embedded height equations and bark ratios specific to northeastern species. We also used regeneration data specific to the study area (Nunery and Keeton 2010). Regional validation studies of NE-FVS have shown adequate predictions of forest growth in northern hardwood forests, with modeled volume predictions within $10-15 \%$ of actual volumes (Yaussy 2000). While the absolute numerical predictions generated by FVS carry uncertainty, the model as used here is appropriate for comparing relative differences among management prescriptions (Ray et al. 2009a, Nunery and Keeton 2010). Site-specific individual tree data (species, dbh, live or dead) and environmental characteristics (elevation, slope, aspect) for the 42 sites served as inputs into FVS.

We implemented four alternative silvicultural prescriptions in FVS to determine their relative influence on $\mathrm{C}$ storage, timber production, and bird biodiversity within and across sites (Table 1). One prescription was a passive "no-management" scenario. We modeled three active management prescriptions (Nunery and Keeton 2010) representative of silvicultural systems used commonly in the Northeast, but modified to encompass a range of harvesting intensities (harvesting frequency and structural retention). The most intensive harvesting practice was represented by a clearcut, with complete removal of all trees $>5 \mathrm{~cm} \mathrm{dbh}$ at the outset of the simulation and again 80 years later. A shelterwood represented greater structural retention, with the initial harvest implemented at year 1 . Under this prescription each partial harvest was followed by an overstory removal cut 20 years later but with retention of 6 legacy trees/ha. An uneven-aged prescription was represented by an individual tree selection (ITS) system, with harvesting directed toward diameter classes with stem densities above target levels. The model routine included both background regeneration inputs at 10 -year time steps and pulses of postharvest regeneration modified by treatment to reflect canopy closure differences following Nunery and Keeton (2010).

FVS simulations produced estimates of $\mathrm{C}$ storage, timber production, and forest stand structural characteristics. In situ $\mathrm{C}$ storage was calculated based on aboveground biomass (live and dead) estimated using species group-specific allometric equations from Jenkins et al. (2003). For simulations involving timber harvesting, FVS also tracked $\mathrm{C}$ fluxes to and among wood products pools from production to disposal using life cycle data from Smith et al. (2006). Carbon pools resulting from harvest, each with their own rates of release of $\mathrm{C}$ to the atmosphere or flux to another $\mathrm{C}$ pool, included coarse woody debris (remaining on site), wood products burned for energy, wood products in use, and landfilled wood and paper. FVS does not currently estimate soil C stocks because they are highly variable and do not respond to management actions in a uniform manner (Hoover and Rebain 2011). FVS does track coarse root biomass as a ratio relative to aboveground biomass, but because other pools including soil $\mathrm{C}$ and fine roots are not modeled we did not include 
TABLE 1. Silvicultural prescriptions applied to 42 northern hardwood forest sites (USA) in a 100-year simulation in the Forest Vegetation Simulator (FVS) model.

\begin{tabular}{|c|c|c|c|}
\hline Prescription & Harvesting frequency & $\begin{array}{l}\text { Structural } \\
\text { retention }\end{array}$ & Description \\
\hline Clearcut & high ( 80 years) & none & $\begin{array}{l}\text { clearcut: } 2004,2084 \\
\text { remove slash from site; } \\
\text { commercial thin when stand fully stocked }\end{array}$ \\
\hline Shelterwood & low $(>100$ years $)$ & medium & $\begin{array}{l}\text { shelterwood: } 2004 \text {, residual basal area } 14 \mathrm{~m}^{2} / \mathrm{ha} \\
\text { removal cut in } 2024 \text { of trees } \geq 15 \mathrm{~cm} \text { diameter, } \\
\text { retain } 6 \text { legacy trees } / \text { ha; } \\
\text { leave slash on site; } \\
\text { commercial thin when stand fully stocked }\end{array}$ \\
\hline Individual tree selection (ITS) & low (30-year entry cycle) & high & $\begin{array}{l}\text { harvest individual trees with target } q \text {-factor of } 1.3 \text {; } \\
\quad \text { residual basal area } 19 \mathrm{~m}^{2} / \text { ha; } \\
\text { retain } 12 \text { legacy trees } / \text { ha (average diameter } 41 \mathrm{~cm} \text { ) }\end{array}$ \\
\hline No management & none & high & no active management simulated \\
\hline
\end{tabular}

belowground $\mathrm{C}$ in our estimates. Predicted timber production was measured as the average annual volume of merchantable timber harvest per hectare, based on input harvest schedules and simulated tree growth. In addition to time-step-specific outputs, we calculated mean $\mathrm{C}$ storage (megagrams per hectare) and mean timber harvest (cubic meters per hectare) for each site under each management prescription for the simulation period.

\section{Bird occurrence models}

We measured the capacity of forests to support biodiversity as the likelihood of occupancy by a set of terrestrial forest birds. Although one taxon may not encompass the habitat needs of all species, the bird community collectively uses a variety of forest structures and ages and therefore is considerably more informative than an assessment of a single species or proxy of biodiversity. To predict how forest management practices would affect bird populations, we modeled the relationship between FVS forest structure outputs and occupancy $(\psi)$, the probability that a site was occupied by a species. The species set consisted of all territorial, terrestrial birds with relatively small home ranges and sufficient detections ( $>10$ sites) for modeling (common and scientific names of the 51 species are provided in Appendix B). We implemented single-season occupancy models (MacKenzie et al. 2002) in MARK 5.1 (White and Burnham 1999) using data from all 533 original sites, which allowed assessment of bird responses to a range of vegetation conditions. For all species, two types of predictive covariates were used (Table 2): (1) forest structure metrics expected to influence occurrence of birds (e.g., Hobson and Schieck 1999, MacFaden and Capen 2002), and (2) patch and landscape metrics that we previously demonstrated to be important to bird occupancy (Schwenk and Donovan 2011). The latter covariates improved occupancy estimates by accounting for the landscape context of the simulation sites. The four forest structure covariates were calculated from field measurements described previously with NED-2 software (Twery et al. 2005). Basal area of live trees was selected as a metric of how forest stand structure affects bird occurrence. Basal area of live conifers was selected based on numerous studies documenting the importance of conifer trees (or their absence) to habitat selection. Basal area of standing dead trees primarily indicated snag availability, recognizing the importance of dead trees to cavity-nesting, insectivorous, and other birds, but also indicated structural development more generally. Quadratic mean diameter (QMD) of live trees, which is the diameter of the tree of average basal area, was selected to integrate information about both mean diameter and tree size distribution.

The patch and landscape covariates (Table 2) reflected landscape condition at multiple scales. A categorical variable indicated whether the site was mid- to latesuccessional forest (1) or in early-successional stages (0). Distance to edge indicated distance to the nearest major land cover type, such as agricultural land. Percentage forest and road density within $1 \mathrm{~km}$ reflected major human influences on the surrounding landscape including conversion of forests and development.

Using these occupancy covariates, we generated 16 models for each species. The model set consisted of all possible combinations of the four forest structure covariates (including a model with no covariates). All models included the patch and landscape occupancy covariates. The equation for the model containing all occupancy covariates was as follows:

$$
\begin{aligned}
\operatorname{logit}(\psi)= & \beta_{0}+\beta_{1}(\text { basal area of live trees }) \\
& +\beta_{2}(\text { basal area of live trees })^{2} \\
& +\beta_{3}(\text { basal area of conifers }) \\
& +\beta_{4}(\text { basal area of conifers })^{2} \\
& +\beta_{5}(\text { basal area of dead trees })+\beta_{6}(\mathrm{QMD}) \\
& +\beta_{7}(\mathrm{QMD})^{2}+\beta_{8}(\text { mature forest })^{2} \\
& +\beta_{9}(\text { distance to edge }) \\
& +\beta_{10}(\text { percentage forest within } 1 \mathrm{~km}) \\
& +\beta_{11}(\text { percentage forest within } 1 \mathrm{~km})^{2} \\
& +\beta_{12}(\text { road density }) .
\end{aligned}
$$

The quadratic terms, which were always paired with their corresponding unsquared terms, allowed assess- 
TABLE 2. Covariates used in modeling occupancy for 51 species of landbirds in Vermont (field data collected in 2003 and 2004).

\begin{tabular}{|c|c|c|c|c|c|}
\hline Covariates & Data source & $\begin{array}{l}\text { Accompanied by } \\
\text { quadratic term? }\end{array}$ & $\begin{array}{c}\text { Data set } \\
\text { range } \dagger\end{array}$ & $\begin{array}{l}\text { Data set } \\
\text { median }\end{array}$ & $\begin{array}{l}\text { Change at sites } \\
\text { during forest } \\
\text { simulations? }\end{array}$ \\
\hline \multicolumn{6}{|c|}{ Forest structure variables tested in model set } \\
\hline $\begin{array}{l}\text { Basal area of live trees, } \\
\geq 2.5 \mathrm{~cm} \mathrm{dbh}\left(\mathrm{m}^{2} / \mathrm{ha}\right)\end{array}$ & field measurement & yes & $0.0-59.7$ & 25.3 & yes \\
\hline $\begin{array}{l}\text { Basal area of live conifer } \\
\quad \text { trees, } \geq 2.5 \mathrm{~cm} \mathrm{dbh}\left(\mathrm{m}^{2} / \mathrm{ha}\right)\end{array}$ & field measurement & yes & $0.0-50.7$ & 2.2 & yes \\
\hline $\begin{array}{l}\text { Basal area of standing dead } \\
\text { trees, } \geq 2.5 \mathrm{~cm} \mathrm{dbh}\left(\mathrm{m}^{2} / \mathrm{ha}\right)\end{array}$ & field measurement & no & $0.0-18.4$ & 2.3 & yes \\
\hline $\begin{array}{l}\text { Quadratic mean diameter } \\
\text { (QMD) of live trees, } \\
\geq 2.5 \mathrm{~cm} \mathrm{dbh}(\mathrm{cm})\end{array}$ & field measurement & yes & $0.0-67.0$ & 19.2 & yes \\
\hline $\begin{array}{l}\text { Mature forest (or early } \\
\text { successional) within } 25 \mathrm{~m}\end{array}$ & field assessment & no & $\$$ & $\mathrm{~N} / \mathrm{A}$ & $\begin{array}{l}\text { yes: forest changed } \\
\text { to early successional } \\
\text { for } 19 \text { yr following } \\
\text { harvest }\end{array}$ \\
\hline \multicolumn{6}{|c|}{ Patch and landscape variables appearing in all models: } \\
\hline $\begin{array}{l}\text { Distance to edge of nearest } \\
\text { other land cover type }(\mathrm{m})\end{array}$ & $\begin{array}{l}\text { NLCD }(2001) \S \\
\text { supplemented } \\
\text { by aerial and field } \\
\text { photographs }\end{array}$ & no & $0-2030$ & 150 & $\begin{array}{l}\text { yes: edge distance } \\
\text { reduced to } 20 \mathrm{~m} \\
\text { when mature forest } \\
=\text { "no" }\end{array}$ \\
\hline Percentage forest within $1 \mathrm{~km}$ & NLCD 2001 & yes & $5.7-100$ & 94 & no \\
\hline $\begin{array}{l}\text { Road density within } 1 \mathrm{~km} \\
\left(\mathrm{~km} / \mathrm{km}^{2}\right)\end{array}$ & Vermont e911 roads data & no & $0.0-9.7$ & 0.6 & no \\
\hline
\end{tabular}

ment of a curvilinear relationship between the covariates and occupancy. We included quadratic terms because we expected that for some species occupancy might be greatest at intermediate values of basal area, QMD, or percentage forest in the landscape. We evaluated the importance and effect of covariates on occupancy in a multimodel inference framework with Akaike's Information Criterion (AIC; Burnham and Anderson 2002), which uses information from all models in the set to draw statistical inferences. For each species, relative importance of a covariate was calculated as the sum of AIC weights for the models containing the covariate. We considered a covariate to receive substantial support if its relative importance was $>0.5$; the sum of weights for all models $=1$.

\section{Linking bird occupancy models to FVS simulations}

Combining the FVS simulation outputs with the beta coefficient values from the occupancy models allowed us to predict occupancy for all bird species at each simulation time step (see also Table 2). Values of basal area and QMD were obtained from FVS for each site at each 5-year interval. Covariate values for percentage forest within $1 \mathrm{~km}$ and road density were assumed to remain constant at each site throughout the simulation. Clear-cut and shelterwood harvesting (but not ITS) were assumed to affect covariate values for mature forest and distance to edge as follows. Harvesting changed sites from mid-/late-successional to early-successional forest for 20 years after harvest; i.e., the categorical variable for mature forest was "no" during the first four time steps after harvest (4, 9, 14, and 19 years), and "yes" during all other time steps. This time period was based on studies showing that some early-successional bird species utilize harvested areas at least 15-20 years after harvesting (Keller et al. 2003, Schlossberg and King 2009). During time steps when mature forest was no, distance to edge was reduced to $20 \mathrm{~m}$ to be representative of bird occupancy in small early-successional patches within a larger forest matrix. We chose this distance because harvesting in the study region generally occurs on a small scale and because the range of distances to edge for early successional sites recorded in our data set was small ( 0 $50 \mathrm{~m}$, mean $18.6 \mathrm{~m}$ ). At all other time steps the actual value of distance to edge obtained for each site was used. We calculated a weighted average occupancy for each site/prescription/time step/species combination using the top-ranked models representing $\geq 95 \%$ AIC weight for a given species.

As an aid in presenting and interpreting results, we grouped species into clusters with similar patterns of occupancy, and therefore similar associations with predictor covariates, based on the full set of 533 study sites. For this analysis, we used Proc Distance and Proc Cluster (SAS Institute 2008) to generate a dendrogram of occupancy relationships based on hierarchical agglomerative clustering on the species set (predicted occupancy of each species at each site). We then examined the dendrogram to select a small number of species clusters. 


\section{Multi-criteria decision analysis}

We implemented the MCDA in three parts: (1) estimating partial utilities of objectives when a single prescription was assigned to all sites (single-prescription portfolio); (2) estimating the total utility under different weighting scenarios for single-prescription portfolios; and (3) allowing the assigned prescription to vary among sites (multi-prescription portfolios) to identify the combination of prescriptions that maximized total utility. For part 1, we computed partial utilities for carbon $(C)$, timber $(T)$, and biodiversity $(B)$ for each site $(i)$ and time step given a management prescription $(j)$. We scaled the partial utilities between $0 \%$ and $100 \%$, such that 0 represented the lowest possible scoring and 100 represented the maximum possible scoring for any given objective. The partial utility for $\mathrm{C}$ storage, $U_{C, i, j}$, was calculated as the mean annual $\mathrm{C}$ stored during the 100-year simulation (at site $i$ for prescription $j$ ), divided by the mean annual $\mathrm{C}$ for the site-prescription combination with the maximum $\mathrm{C}$ storage (considering all four prescriptions). Similarly, the partial utility $U_{T, i, j}$ for timber production was calculated as the mean annual volume of merchantable wood produced during the simulation (at site $i$ for prescription $j$ ) divided by the mean annual volume produced for the site and prescription with the maximum timber production.

We calculated the corresponding partial utility for biodiversity for each site and prescription, $U_{B, i, j}$, in several steps. After estimating average occupancy for each bird species during the simulated time period, we rescaled occupancy estimates so that species with greater estimated occupancy (more common species) did not have a disproportionate influence on the utility function. The rescaled occupancy estimates were summed across the 51 species:

$$
B_{i, j}=\sum_{k=1}^{51} \frac{\psi_{i, j, k}}{\psi_{\max , i, j, k}}
$$

where $\psi_{i, j, k}$ was the mean occupancy for an entire simulation (site $i$, prescription $j$, species $k$ ) and $\psi_{\max , i, j, k}$ was the maximum of these occupancy values. The final partial utility converted the bird occupancy scores to the $0-100 \%$ scale:

$$
U_{B, i, j}=\frac{B_{i, j}}{B_{\max , i, j}}
$$

where $B_{\max , i, j}$ was the maximum bird occupancy score among all site-prescription combinations.

In part 2 of the MCDA, we estimated total utility by including weights for management objectives while retaining the assumption that all sites receive the same management prescription. Weights represented preferences or values assigned to the management objectives ( $w_{C}=\mathrm{C}$ weight, $w_{T}=$ timber weight, and $w_{B}=$ biodiversity weight) under the constraint that the weights summed to 1 . We explored a full range of weights to examine how they affected the expected utility for the four prescriptions. For any given scenario, the assigned weights were multiplied by the site-specific partial utilities described in part 1 . The total utility of a management prescription $j$ was the following linear additive model (averaged across the 42 sites):

$$
U_{j}=\frac{\sum_{i=1}^{42} w_{C} \times U_{C, i, j}+w_{T} \times U_{T, i, j}+w_{B} \times U_{B, i, j}}{42} .
$$

In part 3 of the MCDA, we added the ability to differentially manage sites and identify the portfolio $p$ that maximized the total utility across sites. The total utility $\left(U_{p}\right)$ was expressed as in the previous equation, with the addition of a choice vector to identify which prescription $j$ was assigned to each site. For the four prescriptions $j_{1 \rightarrow 4}$, values were binary ( 0 or 1 ) and only one prescription could be chosen per site for the duration of the simulation, resulting in the following total utility for the entire portfolio:

$$
U_{p}=\frac{\sum_{i=1}^{42}\left[\begin{array}{l}
j_{1} \\
j_{2} \\
j_{3} \\
j_{4}
\end{array}\right]\left[\begin{array}{l}
w_{C} U_{C, i, j=1}+w_{T} U_{T, i, j=1}+w_{B} U_{B, i, j=1} \\
w_{C} U_{C, i, j=2}+w_{T} U_{T, i, j=2}+w_{B} U_{B, i, j=2} \\
w_{C} U_{C, i, j=3}+w_{T} U_{T, i, j=3}+w_{B} U_{B, i, j=3} \\
w_{C} U_{C, i, j=4}+w_{T} U_{T, i, j=4}+w_{B} U_{B, i, j=4}
\end{array}\right]}{42} .
$$

Because the partial utilities were scaled between $0 \%$ and $100 \%$ and weights ranged from 0 to $1, U_{p}$ was also scaled between $0 \%$ and $100 \%$.

We considered four weighting scenarios that represented a range of preferences. In one scenario the weights for the objectives were equal; in the other three, one objective was weighted 0.60 and two were weighted 0.20 . For a weighting scenario, the portfolio with the maximum utility was the one where each site was assigned the prescription that maximized the utility at that site. We identified the portfolio with maximum utility under each weighting scenario, and tallied the number of prescriptions of each type that had been assigned.

\section{RESUlts}

\section{Starting condition of forest characteristics and bird occupancy}

At the beginning of the simulation, live basal area at the 42 sites (Appendix A) ranged from 23.0 to $50.5 \mathrm{~m}^{2} /$ ha (mean 29.6) and QMD ranged from 20.8 to $48.0 \mathrm{~cm}$ (mean $28.5 \mathrm{~cm}$ ). Percentage of live basal area composed of conifers ranged from $0 \%$ to $54.9 \%$, with a mean of $7.7 \%$ or $2.6 \mathrm{~m}^{2} /$ ha.

All four forest structure covariates were important to occupancy estimates for multiple species (Table 3), with conifer basal area being important for the most species. A variety of linear and nonlinear associations between covariates and occupancy were apparent. For example, the association between conifer basal area and occupancy was positive for Blackburnian Warbler (Setophaga fusca), negative for Veery (Catharus fuscescens), and 
TABLE 3. Summary of influence of covariate values that varied during forest simulations on occupancy for 51 bird species.

\begin{tabular}{|c|c|c|c|c|c|c|c|}
\hline \multirow[b]{2}{*}{ Occupancy covariates } & \multirow{2}{*}{$\begin{array}{l}\text { Average } \\
\text { relative variable } \\
\text { importance }\end{array}$} & \multirow{2}{*}{$\begin{array}{l}\text { No. species, } \\
\text { most important } \\
\text { variable }\end{array}$} & \multirow{2}{*}{$\begin{array}{l}\text { No. species for which } \\
\text { relative variable } \\
\text { importance }>0.5\end{array}$} & \multicolumn{4}{|c|}{$\begin{array}{l}\text { Nature of covariate relationship, } \\
\text { no. species for which } \\
\text { relative variable importance }>0.5\end{array}$} \\
\hline & & & & + & $\cap$ & - & $\cup$ \\
\hline Basal area of live conifers & 0.55 & 21 & 25 & 11 & 7 & 5 & 2 \\
\hline Basal area of live trees & 0.42 & 12 & 18 & 2 & 4 & 11 & 1 \\
\hline QMD & 0.39 & 11 & 14 & 1 & 10 & 0 & 3 \\
\hline Basal area of standing dead trees & 0.40 & 7 & 12 & 2 & & 10 & \\
\hline \multicolumn{8}{|c|}{ Occupancy covariates included in all models (variable importance not calculated) } \\
\hline Mature forest & & & & $31 \dagger$ & & 12 & \\
\hline Distance to edge & & & & 20 & & 39 & \\
\hline
\end{tabular}

Notes: Key to abbreviation: + , positive relationship or maximum occupancy at large covariate values; $\cap$, intermediate (humpshaped) relationship; -, negative relationship; $\cup, U$-shaped (minimum occupancy at intermediate covariate values). Only covariates with an accompanying quadratic term could result in $\cap$ or $\cup$ relationships. Relative variable importance (range $0-1$ ) is the sum of the AIC weights for each model in a set that contains a given covariate; it is an indicator of the strength of overall support for the covariate among the full model set for a species.

$\dagger$ Includes seven species not detected at early successional sites and for which covariate value therefore was not estimable.

intermediate (i.e., hump-shaped) for Winter Wren (Troglodytes hiemalis). Species associations are presented in Appendix B.

\section{Simulations of changes in forest characteristics over time}

Values of FVS outputs (basal area, total live aboveground biomass, and QMD) showed considerable fluctuation over time and substantial differences among prescriptions (Fig. 2). Harvesting under all three active management prescriptions resulted in substantial decreases in average live, conifer, and dead basal area compared to no management. On average, live basal area (Fig. 2a) and aboveground live biomass (Fig. 2e) were greatest for the no-management prescription and least for the clear-cut prescription. For the first half of the simulation period, live conifer basal area (Fig. 2b) was greatest for the no-management prescription, but subsequently became greater under the ITS and clearcut prescriptions as a result of model regeneration inputs. Basal area of dead trees (Fig. 2c) was consistently greatest in the no-management prescription. Temporal patterns for QMD (Fig. 2d) were stable for the no-management prescription due to compensatory effects of in-growth of small trees and increases in dominant canopy tree sizes. Harvesting decreased QMD except in the case of the shelterwood prescription, where the initial cut resulted in an increase in mean tree diameter, followed by a large decrease after the subsequent overstory removal. Clear-cut QMD was much reduced as an average over two rotations compared to no management, as expected for even-aged management. ITS QMD values were intermediate due to the removal of some canopy trees at each harvest coupled with regeneration and stem development across a range of tree sizes.

\section{Simulations of carbon storage and timber production}

The forest simulations resulted in a clear pattern of increasing $\mathrm{C}$ storage with decreasing intensity of forest management (Fig. 3). Mean C storage for the simulation under the no-management prescription (147.3 Mg C/ha) was more than triple that of the clearcut prescription (46.3 $\mathrm{Mg} \mathrm{C} / \mathrm{ha}$ ). More intensive forest management resulted in greater storage of $\mathrm{C}$ in wood products, but these quantities did not make up for concomitant large reductions in aboveground live biomass (Figs. 2f and 3). Under the simulations, a considerable portion of harvested biomass did not become part of wood products, including wood that remained on site (where it decomposed), was discarded during processing (bark and limbs), or was burned for energy. The decline in C stored in wood products over time (Fig. 2f) reflected relatively short half-lives $(<15 \mathrm{yr})$ projected for certain products, such as wooden pallets and railroad ties. ITS most closely approached the no-management prescription, with mean C storage (112.6 Mg C/ha) $76.4 \%$ of the no-management prescription, of which $12.5 \%(14.1 \mathrm{Mg}$ $\mathrm{C} / \mathrm{ha}$ ) constituted long-term storage in harvested wood products. No management and lower intensity management had higher recruitment rates for snags, which led to an increase in the downed $\log \mathrm{C}$ pool over time.

Annual timber production and volume removals were greatest in the clearcut prescription $\left(2.5 \pm 0.068 \mathrm{~m}^{3} / \mathrm{ha}\right.$, mean and SE for 42 sites), with less harvested in the ITS $\left(2.0 \pm 0.084 \mathrm{~m}^{3} / \mathrm{ha}\right)$ and shelterwood prescriptions $(1.5$ $\pm 0.075 \mathrm{~m}^{3} / \mathrm{ha}$ ). The no-management prescription did not include harvests.

\section{Simulations of changes in bird occupancy over time}

Changes in forest covariates (Fig. 2), plus accompanying changes to distance to edge following harvests, resulted in changes in predicted bird occupancy over time within management prescriptions and differences among management prescriptions (Fig. 4). We grouped the species into five clusters with similar patterns of occupancy (cluster assignments for all species are presented in Appendix B). Species in cluster 1 (which we termed "edge and early successional species"), such 

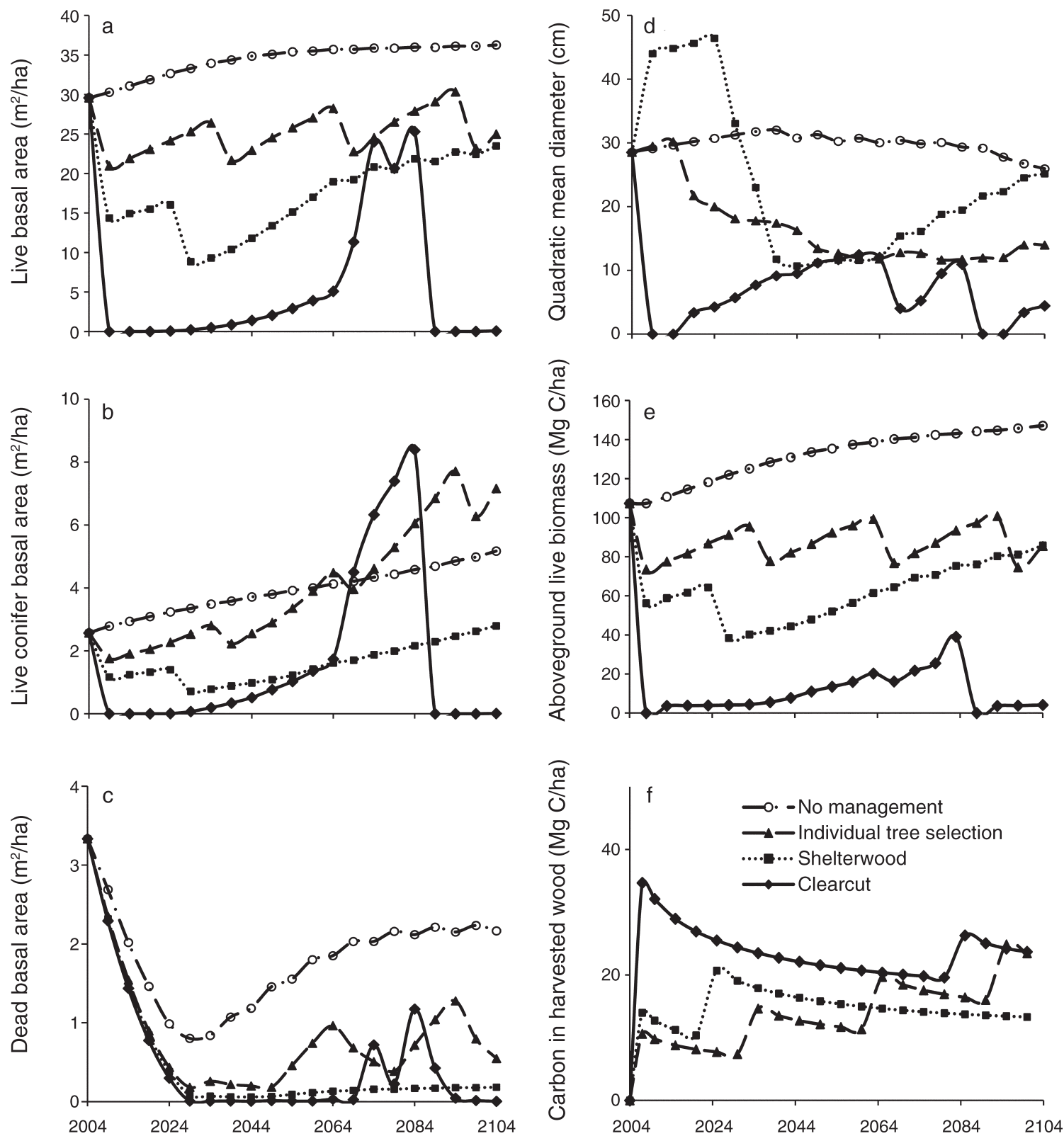

FIG. 2. Results of 100-year simulations (2004-2104) of forest growth under four forest management prescriptions, averaged across 42 northern hardwoods forest sites: (a) basal area of live trees, (b) basal area of live conifer trees, (c) basal area of standing dead trees, (d) quadratic mean tree diameter (QMD), (e) total live aboveground biomass, and (f) carbon stored in harvested wood products (wood is not harvested in the no-management prescription).

as Song Sparrow (Melospiza melodia), showed substantial increases in occupancy when sites were in an early successional state (Fig. 4a, b). They also were associated with relatively unforested landscapes. Cluster 2 species ("species of intermediate forest landscapes"), such as Veery, tended to occur most frequently in landscapes with an intermediate percentage of forest within $1 \mathrm{~km}$ and were not particularly sensitive to local forest management. Cluster 3 species ("forest interior species"), such as Black-throated Green Warbler (Setophaga virens), decreased in occurrence following intensive harvesting and were more likely to occupy sites with greater values of percentage forest within $1 \mathrm{~km}$. Like forest interior species, species of cluster 4 ("coniferous forest") were associated with highly forested landscapes, but occupancy was greater in forests with higher conifer basal areas. In general, Blackburnian Warbler and other coniferous forest species did not respond as negatively to harvesting as forest interior species. Cluster 5 species tended to occur near edges and in early successional sites within landscapes that otherwise were predominantly forested, so we termed them "early successional/forest 


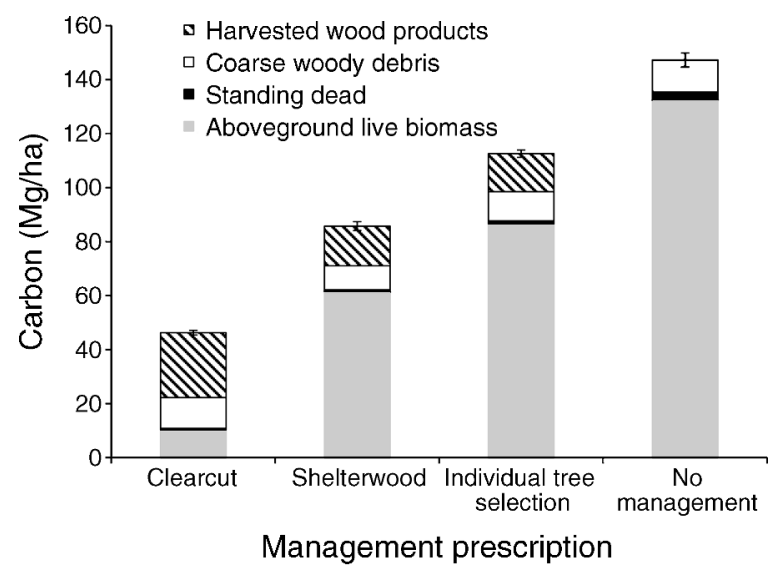

FIG. 3. Predicted carbon stocks (mean \pm SE), including stocks stored in harvested wood products, under different management prescriptions applied to 42 northern hardwood forest sites (average for 100-year simulations).

matrix species." Chestnut-sided Warbler (Setophaga pensylvanica) is representative of this cluster.

Considering all species collectively, the most substantial changes over time occurred in the clearcut prescrip- tion, reflecting its intensive harvest regime (Fig. 4a). For 20 years following clearcuts, occupancy predictions for early successional species (clusters 1 and 5) increased while they decreased for forest interior species. Increasing basal area of conifers as regeneration proceeded positively affected coniferous forest species until the second clearcut. In the shelterwood prescription (Fig. 4b), early-successional and forest interior species exhibited similar responses to harvesting as in the clearcut prescription, except that fluctuations were more muted and of longer duration, reflecting the less intensive harvest regime implemented over a longer time period. By maintaining greater stand structural complexity as measured by vegetation covariates, the ITS prescription (Fig. 4c) resulted in occupancy patterns similar to the no-management prescription (Fig. 4d). For both of these prescriptions, occupancy of early-successional species was suppressed relative to the more intensive prescriptions and was much more stable over time. Conversely, forest interior and coniferous forest species were associated with more mature forests and collectively showed greater occupancy under the ITS and nomanagement prescriptions.

- Cluster 1, edge and early successional

Cluster 5 , early successional/forest matrix $\square$ Cluster 4 , coniferous forest

Cluster 2, intermediate forest landscapes $\quad$ Cluster 3 , forest interior
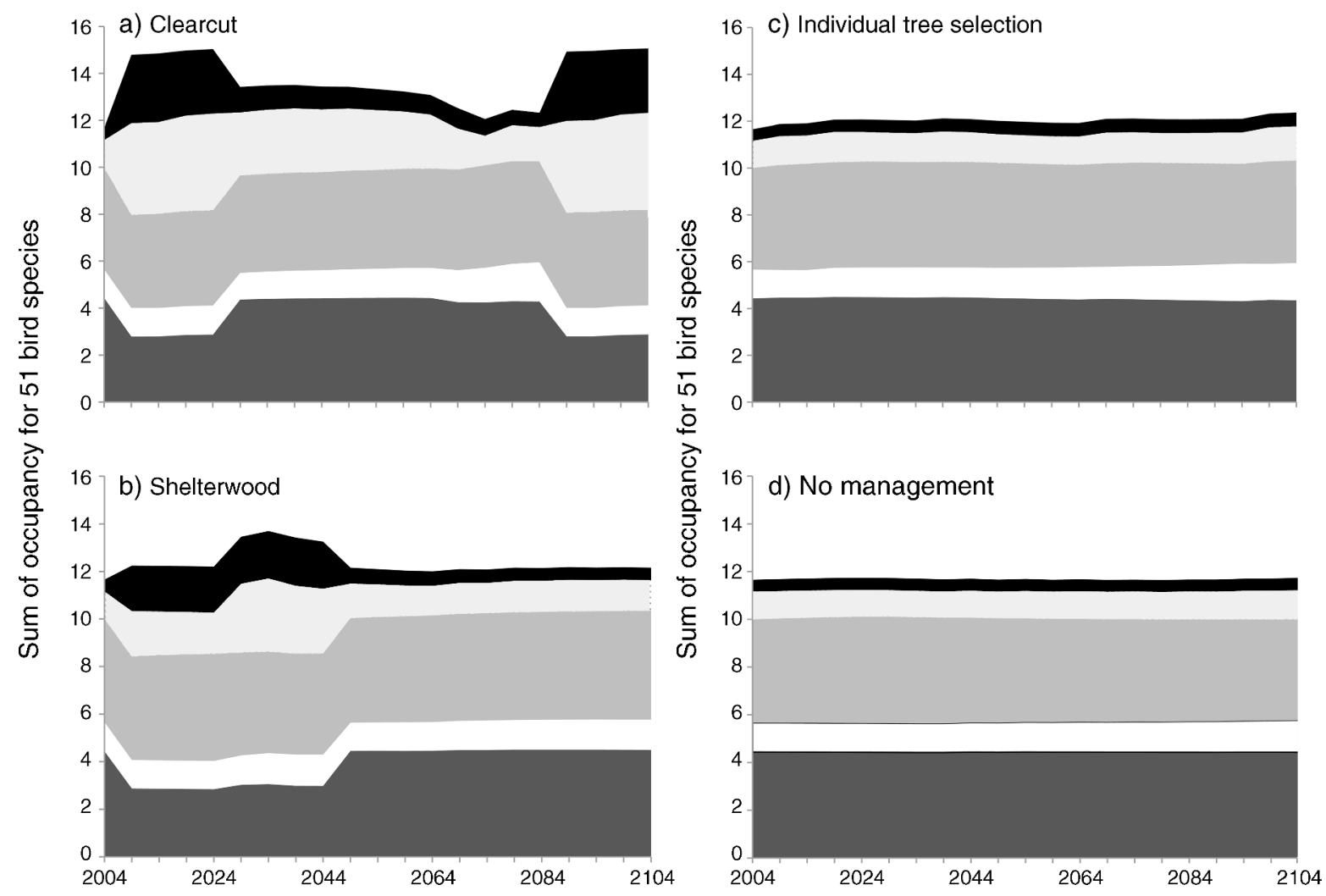

FIG. 4. Average predicted occupancy summed for all 51 forest birds species, grouped in clusters, for the four management prescriptions: (a) clearcut with short harvest interval (clearcuts in 2004 and 2084), (b) shelterwood with long harvest interval (partial harvest in 2004, removal cut in 2024), (c) individual tree selection, 30-year entry cycle, and (d) no management. 


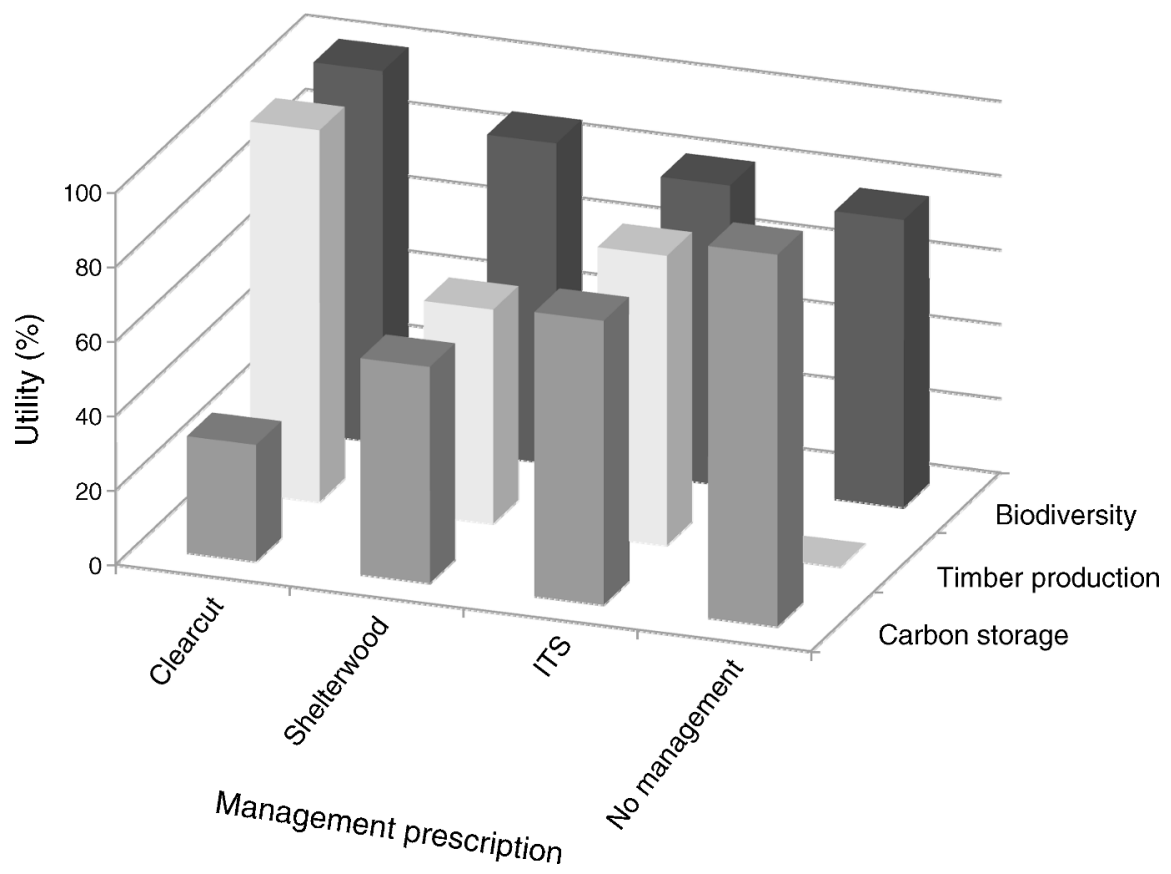

FIG. 5. Expected utilities for carbon storage, timber production, and bird occupancy based on averages for 100-year simulations when all 42 sites received the same prescription. Prescription utilities are scaled relative to each other such that the prescription with the maximum utility for an endpoint is assigned $100 \%$ utility. ITS is individual tree selection. Biodiversity utilities presume small-scale forest treatments within predominantly forested landscapes.

\section{Multi-criteria decision analysis}

In part 1 of the MCDA, where portfolios consisted of a single prescription assigned to all sites, the partial utilities for an objective were clearly related to management prescription (Fig. 5). The no-management prescription utility was greatest for $\mathrm{C}$ storage but least for timber production and biodiversity; the clearcut prescription utility had the reverse pattern. Although the ITS prescription utility was not the greatest for any objective, it was consistently high for all objectives (Fig. 5).

Sites varied more in estimated annual timber production, given the same management prescription, than they did for $\mathrm{C}$ storage or biodiversity (Table 4). Timber production was especially variable for the shelterwood prescription, with the most productive site estimated to yield greater than three times the volume of the least productive site. $\mathrm{C}$ storage and biodiversity values varied across sites by less than a factor of 2 when all sites received the same prescription.

In the part 2 of the MCDA, we identified the prescription that maximized total utility when all sites received the same prescription and when weighting factors were applied to the three objectives. Which prescription maximized total utility depended on the assigned weights (Fig. 6). If the $\mathrm{C}$ storage weight was $\leq$ 0.3 , the clearcut prescription had the greatest total utility. The no-management prescription generally ranked highest when the $\mathrm{C}$ storage weight was $>0.3$ and the timber weight was $<0.1$ to 0.2 . Selection harvesting (ITS) had the greatest utility for the remaining combinations of values. The no-management and clearcut prescriptions varied strongly depending on the assigned weights, with total relative utilities ranging from 0 (for no management if timber weight $=1.0$ ) and 0.3 (for clearcut if $\mathrm{C}$ weight $=1.0$ ) to 1 . The ITS prescription frequently was the second-ranked prescription and consistently had a high total relative utility that was $75-80 \%$ of the maximum possible utility. The shelterwood prescription was never the highest ranked prescription.

In the case where sites could be managed differentially (MCDA part 3), multi-prescription portfolios achieved higher total utilities than single-prescription portfolios under the combinations of weights we investigated (Fig. 7). The dominant prescription when optimizing allocation was consistent with the pattern observed for singleprescription portfolios (Figs. 6 and 7). Although multiportfolio prescriptions were favored, in all cases the utility of at least one single-prescription portfolio nearly equaled the maximum utility (Fig. 7). In fact, utility of the all-ITS portfolio was $\geq 90 \%$ of the maximum utility for all weights we tested. The all-clearcut portfolio also attained $90 \%$ or more of the maximum utility whenever the weight for $\mathrm{C}$ storage was $\leq 0.33$. On the other hand, the all-shelterwood portfolio utility did not exceed $90 \%$ of maximum utility for any weighting scenario, and none of the maximum utility portfolios included shelterwood prescriptions. When weights for $\mathrm{C}$ storage were large, the utility of the portfolio exclusively consisting of 
TABLE 4. Comparison of site variability among 42 sites for C storage, timber production, and bird occurrence (annual averages for 100 -year simulation, summarized for cases when all sites received the same prescription).

\begin{tabular}{|c|c|c|c|c|c|c|c|c|c|}
\hline \multirow[b]{2}{*}{ Prescription } & \multicolumn{3}{|c|}{ C storage $(\mathrm{Mg} / \mathrm{ha})$} & \multicolumn{3}{|c|}{ Timber production $\left(\mathrm{m}^{3} / \mathrm{ha}\right)$} & \multicolumn{3}{|c|}{$\begin{array}{l}\text { Probability of occupancy } \\
\text { (sum of } 51 \text { species) }\end{array}$} \\
\hline & Mean & SD & $\mathrm{CV \dagger}$ & Mean & $\mathrm{SD}$ & $\mathrm{CV} \dagger$ & Mean & $\mathrm{SD}$ & $\mathrm{CV} \dagger$ \\
\hline Clearcut & 46 & 6 & 12 & 2.5 & 0.44 & 18 & 13.7 & 0.78 & 6 \\
\hline Shelterwood & 86 & 11 & 12 & 1.4 & 0.47 & 33 & 12.4 & 0.72 & 6 \\
\hline ITS & 113 & 9 & 8 & 2.0 & 0.55 & 28 & 12.1 & 1.02 & 8 \\
\hline No management & 147 & 16 & 11 & $0 \ddagger$ & & & 11.7 & 0.93 & 8 \\
\hline
\end{tabular}

$\dagger$ Coefficient of variation ([standard deviation $/$ mean] $\times 100 ; \%)$.

t The no-management prescription did not entail timber harvests.

no management nearly equaled the maximum possible utility.

\section{Discussion}

Our findings offer new insights for sustainable forest management, demonstrating the utility of analytical approaches that combine forest simulation modeling with MCDA. These approaches have great potential for evaluating trade-offs among multiple management objectives. The framework we present can be readily modified to incorporate (1) alternative models or (2) additional modules to consider factors such as natural disturbance and climate change. Previous researchers have noted the usefulness of MCDA (Kangas and Kangas 2005, Wolfslehner and Seidl 2010), but ours is the first to integrate carbon and timber objectives with biodiversity objectives represented by a large set of bird species. An emerging theme from our study was that variation in the effects of management prescriptions, site characteristics, and weights placed on management objectives meant that no single management approach had the greatest utility in all circumstances. Therefore, a diversity of silvicultural approaches is likely to be preferable and simultaneously accommodating all three objectives requires compromises among them. Providing a full range of ecosystem goods and services requires holistic, landscape-scale management in which a diversity of silvicultural and conservation approaches are applied in tandem (Lindenmayer and Franklin 2002, Keeton 2007).

With the recent expansion of both voluntary and compliance carbon market systems, demand is increasing for forest carbon management approaches that can be integrated with other objectives, including timber, non-timber forest products, wildlife, water, aesthetics, and recreation (Jackson et al. 2005, Ray et al. 2009b). Our analysis framework demonstrated an intuitively understandable approach to integrating these objectives. Our findings are consistent with a number of recent studies showing that either no management or silvicultural approaches emphasizing less frequent harvesting and greater structural retention result in the greatest net carbon storage (Harmon and Marks 2002, Seidl et al. 2007, Swanson 2009, Nunery and Keeton 2010). Our simulations indicated that considerable carbon can be stored in wood products, but because of losses of wood

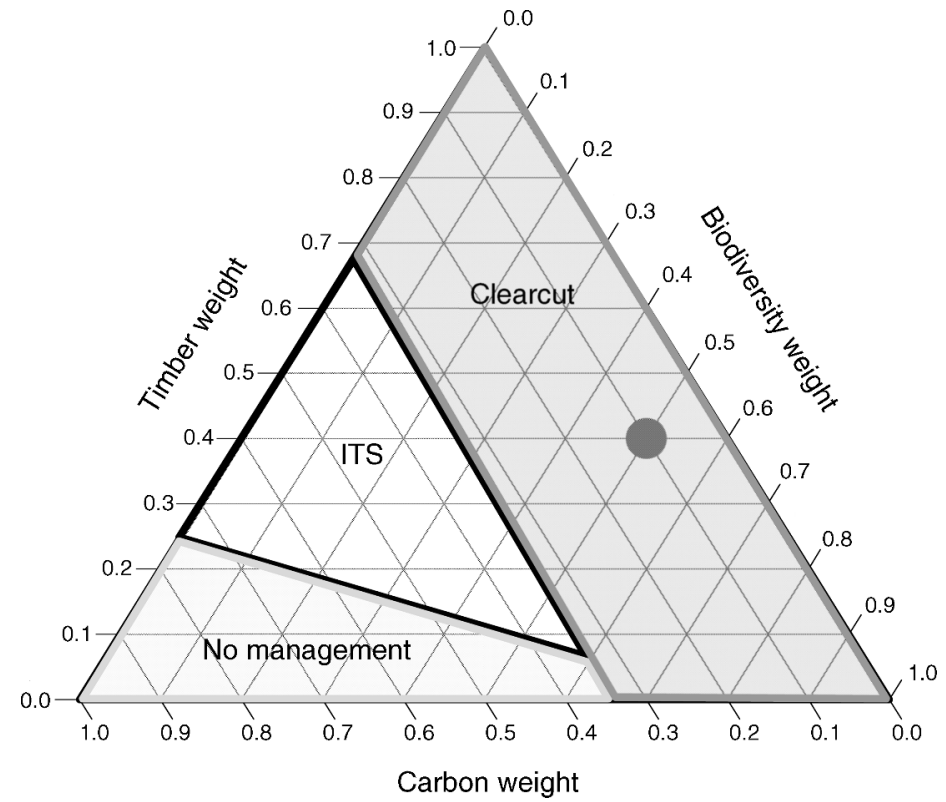

FIG. 6. Management prescriptions with the highest relative utilities given all possible combinations of values (weights) assigned to the objectives of carbon storage, timber production, and biodiversity. For example, the illustrated point occurs at a carbon storage weight of 0.1 , a timber production weight of 0.4 , and a biodiversity weight of 0.5 . Given this combination of weights, the clearcut management prescription has the highest total utility. 

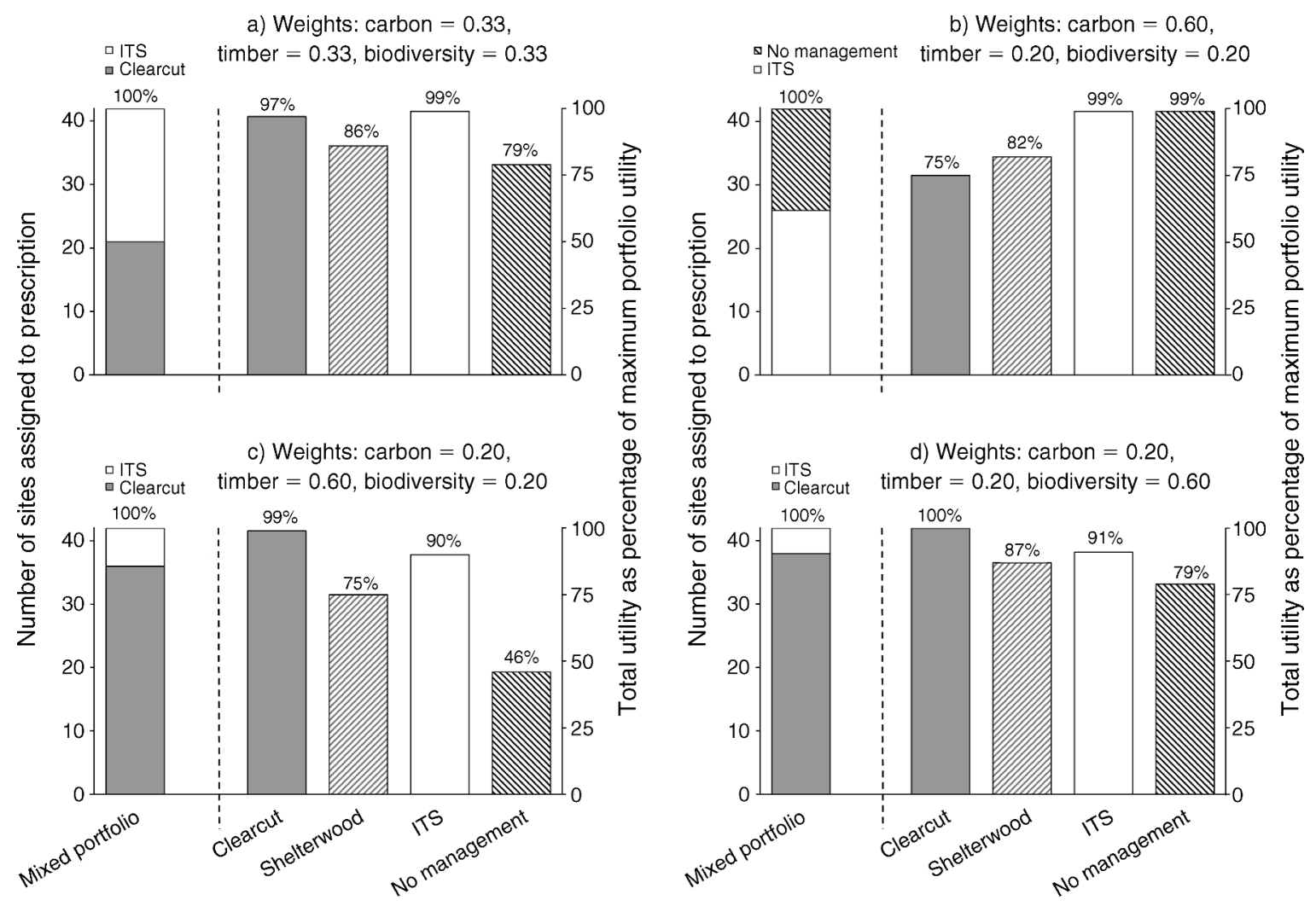

FIG. 7. Utilities for portfolios given four combinations of weights (a, b, c, d) for the objectives of carbon storage, timber production, and biodiversity. In each panel, the bar to the left of the vertical dashed line represents the portfolio that maximizes total utility (total utility $=100 \%$ ), allowing for sites to be assigned different management prescriptions (segment heights represent the number of sites assigned to each prescription; ITS, individual tree selection). The four bars on the right of each panel represent portfolios consisting of all sites assigned the same management prescription, with bar heights equal to total utility as a percentage of the maximum total utility.

during production processes, the relatively short (e.g., 150 years) life cycle of many wood products (Smith et al. 2006), and decay following eventual disposal, the wood products pool (under intensive wood management) is insufficient to compensate for carbon storage in less intensively managed forests. Our findings also indicated that the less timber harvested, the greater the total (in situ + wood products) amount of carbon likely to be stored over the long term as an annual average. But the results also clearly showed that there are intermediate approaches, particularly when silvicultural prescriptions are coordinated across multiple sites, that could be employed to yield a mix of carbon storage and timber production. Most likely applied forest carbon management will involve some combination of more and less intensive silvicultural approaches depending on the economic incentives offered by carbon markets and the overall management objectives of a given landowner (Ryan et al. 2010, Keeton et al. 2011).

We should point out that our conclusions on carbon implications depend upon the approaches and assumptions we used, including timing of harvests and fate of wood products. Two considerations with potential to modify our conclusions are soil carbon and substitution of wood for more fossil-fuel-intensive alternatives (termed "substitution effects"). Soil carbon represents a significant $\mathrm{C}$ pool in forests, but responses of soil $\mathrm{C}$ to management are highly variable and uncertain, and consequently are not tracked by FVS (Hoover and Rebain 2011). Some studies have found that intensive management can result in large losses of soil $\mathrm{C}$, whereas others have reported much more modest effects; the intensity of soil scarification, the methods of harvesting and site preparation, and soil type are important in determining soil C fluxes (Yanai et al. 2003, Jandl et al. 2007, Nave et al. 2010). If our analyses had assumed that harvesting induced substantial losses of soil $\mathrm{C}$, then the differences in $\mathrm{C}$ storage among the management prescriptions we examined would have been even more pronounced. By contrast, consideration of substitution effects might have had the opposite effect. Some studies that have incorporated assumptions about the offset of emissions achieved by replacing more energy-intensive building materials with wood have concluded that intensified harvesting can reduce net emissions (PerezGarcia et al. 2005, Eriksson et al. 2007). Given the host of factors necessary for a comprehensive life cycle analysis, such as carbon emissions in harvesting and 


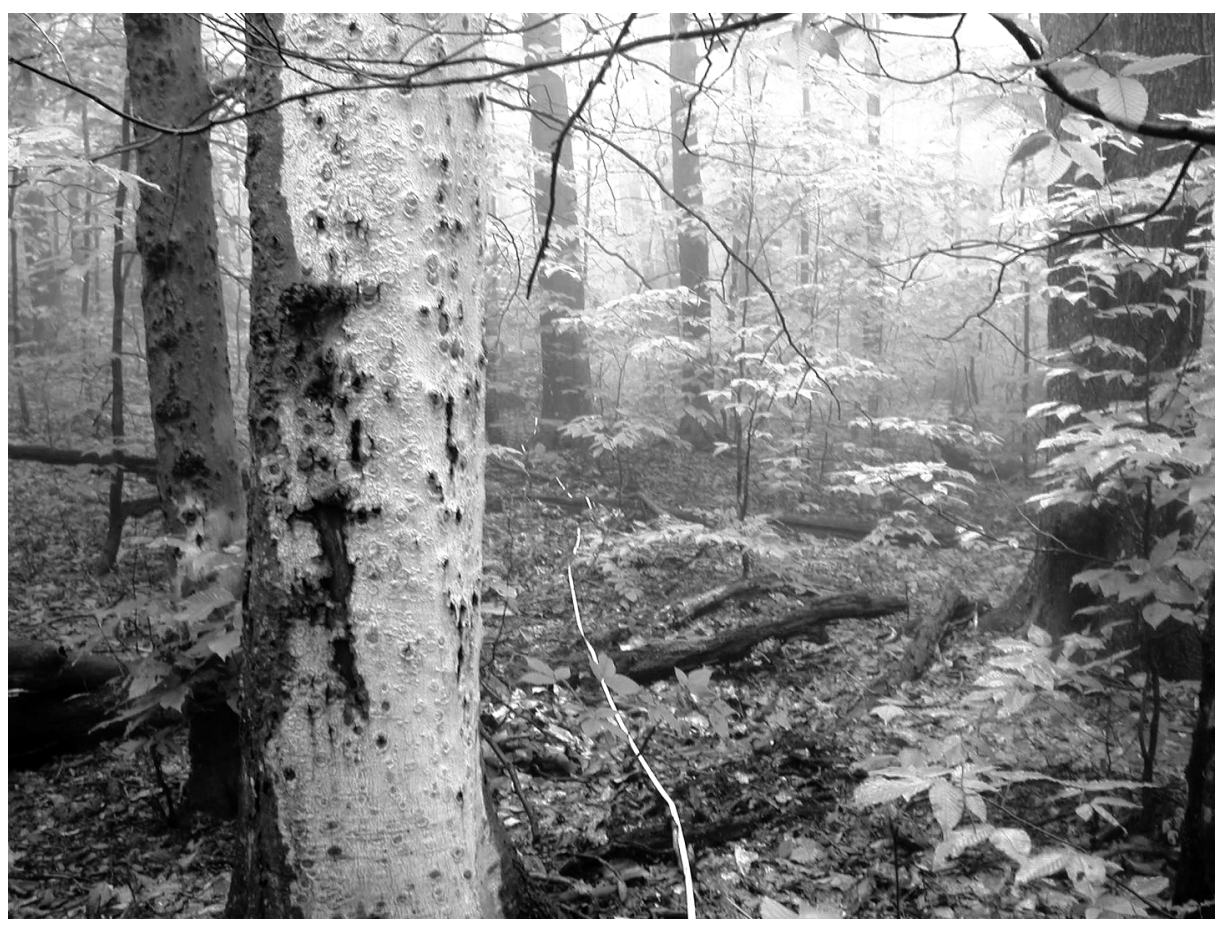

Plate 1. Example of one of 42 northern hardwood forest sites used in simulation of forest management and comparison of predicted future ecosystem services. A white measuring tape used in field sampling is visible in the lower central portion of the image. Photo credit: Charley Eiseman.

transporting wood and cradle-to-grave carbon implications of alternatives, we did not attempt to incorporate substitution effects into our analysis. Both soil carbon and substitution effects can be readily incorporated into MCDA, however, if adequate data are available.

Our study is one of the first to link projection of future forest condition to empirically derived models of wildlife occurrence in the context of multifunctional forest management. It therefore establishes a useful framework for future analyses applicable where diversity of species and natural communities are to be considered, as is required for the U.S. National Forest System. Most prior multi-objective studies, including the few studies that have simultaneously considered carbon storage, timber production, and biodiversity (e.g., Seely et al. 2004, Fürstenau et al. 2007, Briceño-Elizondo et al. 2008), have represented biodiversity by a few species or by indirect proxies of biodiversity (such as density of deadwood). By assessing the probability of occupancy for multiple species simultaneously, our framework presents an alternative to analytical approaches heavily dependent on indicator species for assessing biodiversity.

We found that bird species responded most strongly to the more intensive harvesting practices (clearcut, shelterwood prescriptions). Given the heavily forested landscape in which sites were located and the small patch size of harvests, the predicted positive response of species following intensive harvesting tended to be of a greater magnitude than the negative response of species most common under late successional conditions. The net result was that more intensive prescriptions received larger biodiversity utility values. Results would differ for large clearcuts or fragmented landscapes. The patterns of predicted bird occurrence we observed were generally consistent with studies that have examined how birds respond to silvicultural practices in the northeastern United States (Thompson and Capen 1988, Germaine et al. 1997, Hagan et al. 1997, Costello et al. 2000, Keller et al. 2003, Goodale et al. 2009). Dense stands of seedlings and saplings with low basal area and QMD, which are characteristic of initial years following harvests in an even-aged system, provide high quality habitat for birds that forage on the ground and in low foliage (Keller et al. 2003). Examples of such species from our study are Common Yellowthroat (Geothlypis trichas; cluster 1) and White-throated Sparrow (Zonotrichia albicollis; cluster 5). More mature or less intensively managed stands, which have greater basal area and QMD than recently harvested even-aged systems, offer new niches and greater vertical complexity for species that use upper canopy foliage, bark, and cavities, but provide fewer resources for species of low foliage (Keller et al. 2003). Red-eyed Vireo (Vireo olivaceus; cluster 3) and Brown Creeper (Certhia americana; cluster 4) are examples of species from our study characteristic of more mature and complex forests. Species less sensitive to management appeared to use a wide range of forest types or occur more frequently in forests of intermediate 
age and structure, such as Black-capped Chickadee (Poecile atricapillus; cluster 2).

Because the rank order of partial utilities for the four silvicultural prescriptions differed for the three management objectives, the weights assigned to the objectives strongly influenced which prescriptions and portfolios were scored as optimal. Of the three objectives, timber production exhibited the greatest differences among prescription partial utilities (especially given the lack of harvesting under the no-management prescription). By contrast, prescriptions were most similar in their partial utilities for the biodiversity objective. The similarities were not due to a lack of effect of silvicultural prescriptions on individual species, but rather because reductions in occurrence in some species tended to be counterbalanced by increases in other species. A relatively equal assignment of weights among objectives allowed a diversity of prescription allocations to approach the optimal solution, whereas heavy weighting on a particular objective tended to favor prescriptions on extreme ends of the harvesting intensity spectrum. Similar patterns have been reported in other multi-objective studies. For example, Fürstenau et al. (2007) found that when stakeholders strongly favor a particular objective (as in the case of forest owners preferring timber income), the optimal management strategy represents one extreme end of the intensity spectrum (intensively managed pine stands).

In addition to identifying optimal management solutions, another application of the MCDA methodology is in better understanding trade-offs among both objectives and prescriptions. This application is valuable because many landowners own and manage their forests for multiple objectives (Butler et al. 2007). Users can systematically alter weights for objectives, and observe the gains and losses in utility for each objective. For example, an extreme weighting on carbon storage results in assignment of all sites to no management and hence a complete absence of timber production (given our simulation assumptions). A less extreme weighting on carbon storage results in a mixed portfolio of ITS and no-management sites, which has both high carbon storage and some timber production. Similarly, an extreme weighting on timber production results in intensive management and limited carbon storage, whereas a more moderate weighting results in greater carbon storage with little loss in timber production. Thus, we found that relatively equitable assignment of weights prevents extreme trade-offs among objectives and allows moderate to high utility to be realized for each objective.

While the MCDA methodology we present is flexible enough to apply in many contexts, we should point out several considerations in interpreting and applying the results of this analysis both within and beyond the study region. First, for several reasons managers may wish to place a greater value on late-successional, more structurally complex forests than reflected in this analysis. Such forests may provide services including watershed protection, riparian function, soil retention, genetic resources, and aesthetic experiences that we did not consider (de Groot et al. 2002, Keeton et al. 2007). They may also harbor species of conservation concern not found in simpler or younger forests (Fischer et al. 2006). Such considerations can readily be addressed within the MCDA framework. Second, landscape context matters (Fischer et al. 2006, Kupfer et al. 2006). Our focal study sites were located in a mostly unfragmented forested landscape, which has important implications for the biodiversity results. In such landscapes, our findings that moderate levels of harvesting may have beneficial effects on biodiversity appear reasonable because adverse effects to forest interior species are not expected to be large (Rodewald and Yahner 2001, Thompson et al. 2002). They also are consistent with arguments that early successional species are of high conservation concern in eastern North America and can benefit from regeneration induced by silvicultural practices (Hunter et al. 2001, DeGraaf and Yamasaki 2003). However, our findings are unlikely to translate well to landscapes where forests are already substantially fragmented. In such landscapes, populations of late successional species may be under stress due to lack of habitat and increased risks from edge predators and nest parasites (Donovan et al. 1995, Fischer and Lindenmayer 2007). A final consideration involves uncertainty, which is inherent in multi-criteria analyses involving models of future conditions (Wolfslehner and Seidl 2010). The uncertainty most readily addressed is the current and future preferences of forest management stakeholders, because our analyses presented results involving a spectrum of weights for objectives. More difficult to quantify are uncertainties related to the FVS model and bird occurrence models. Recognizing that we did not undertake a formal model uncertainty analysis, we caution readers not to assume that small differences between portfolios of silvicultural prescriptions are conclusive evidence of superiority of one portfolio or prescription over another.

\section{ACKNOWLEDGMENTS}

We thank N. Charney, T. Collingwood, R. DeMots, C. Eiseman, A. Gregor, S Harris, K. Manaras, J. Panek, S. Wilson, and T. Yuta for conducting field surveys. We also appreciate assistance from C. Bettigole, E. Buford, R. Long, B. Mitchell, and J. O'Neil-Dunne and the many landowners who granted access to their property. D. Capen, D. King, and two anonymous reviewers offered helpful comments on the manuscript. Funding was provided by the USDA Northeastern States Research Cooperative, the McIntire-Stennis Cooperative Forestry Program, and the USGS Vermont Cooperative Fish and Wildlife Research Unit. Use of trade-names in this article does not imply endorsement by the federal government. The Vermont Cooperative Fish and Wildlife Research Unit is jointly supported by the U.S. Geological Survey, the University of Vermont, the Vermont Department of Fish and Wildlife, and the Wildlife Management Institute.

\section{Literature Cited}

Belton, V., and T. S. Stewart. 2002. Multiple criteria decision analysis: an integrated approach. Kluwer Academic, Norwell, Massachusetts, USA. 
Birdsey, R., K. Pregitzer, and A. Lucier. 2006. Forest carbon management in the United States: 1600-2100. Journal of Environmental Quality 35:1461-1469.

Briceño-Elizondo, E., D. Jäger, M. J. Lexer, J. Garcia-Gonzalo, H. Peltola, and S. Kellomäki. 2008. Multi-criteria evaluation of multi-purpose stand treatment programmes for Finnish boreal forests under changing climate. Ecological Indicators $8: 26-45$.

Burnham, K. P., and D. R. Anderson. 2002. Model selection and multimodel inference: a practical information-theoretic approach. Second edition. Springer-Verlag, New York, New York, USA.

Butler, B. J., M. Tyrrell, G. Feinberg, S. VanManen, L. Wiseman, and S. Wallinger. 2007. Understanding and reaching family forest owners: lessons from social marketing research. Journal of Forestry 105:348-357.

Costello, C. A., M. Yamasaki, P. J. Pekins, W. B. Leak, and C. D. Neefus. 2000. Songbird response to group selection harvests and clearcuts in a New Hampshire northern hardwood forest. Forest Ecology and Management 127:4154.

Crookston, N. L., and G. E. Dixon. 2005. The forest vegetation simulator: a review of its structure, content, and applications. Computers and Electronics in Agriculture 49:60-80.

Daily, G. C., S. Alexander, P. R. Ehrlich, L. Goulder, J. Lubchenco, P. A. Matson, H. A. Mooney, S. Postel, S. H. Schneider, D. Tilman, and G. M. Woodwell. 1997. Ecosystem services: benefits supplied to human societies by natural ecosystems. Issues in Ecology 2:1-16.

DeGraaf, R. M., and M. Yamasaki. 2003. Options for managing early-successional forest and shrubland bird habitats in the northeastern United States. Forest Ecology and Management 185:179-191.

de Groot, R. S., M. A. Wilson, and R. M. J. Boumans. 2002. A typology for the classification, description and valuation of ecosystem functions, goods and services. Ecological Economics 41:393-408.

Diaz-Balteiro, L., and C. Romero. 2008. Making forestry decisions with multiple criteria: a review and an assessment. Forest Ecology and Management 255:3222-3241.

Donovan, T. M., F. R. Thompson III, J. Faaborg, and J. R. Probst. 1995. Reproductive success of migratory birds in habitat sources and sinks. Conservation Biology 9:13801395.

Ehrlich, P. R., and A. H. Ehrlich. 1992. The value of biodiversity. Ambio 21:219-226.

Eriksson, E., A. R. Gillespie, L. Gustavsson, O. Langvall, M. Olsson, R. Sathre, and J. Stendahl. 2007. Integrated carbon analysis of forest management practices and wood substitution. Canadian Journal of Forest Research 37:671-681.

Farley, J. 2008. The role of prices in conserving critical natural capital. Conservation Biology 22:1399-1408.

Fischer, J., and D. B. Lindenmayer. 2007. Landscape modification and habitat fragmentation: a synthesis. Global Ecology and Biogeography 16:265-280.

Fischer, J., D. B. Lindenmayer, and A. D. Manning. 2006 Biodiversity, ecosystem function, and resilience: ten guiding principles for commodity production landscapes. Frontiers in Ecology and the Environment 4:80-86.

Fürstenau, C., F. Badeck, P. Lasch, M. J. Lexer, M. Lindner, P. Mohr, and F. Suckow. 2007. Multiple-use forest management in consideration of climate change and the interests of stakeholder groups. European Journal of Forest Research 126:225-239.

Germaine, S. S., S. H. Vessey, and D. E. Capen. 1997. Effects of small forest openings on the breeding bird community in a Vermont hardwood forest. Condor 99:708-718.

Goodale, E., P. Lalbhai, U. M. Goodale, and P. M. S. Ashton. 2009. The relationship between shelterwood cuts and crown thinnings and the abundance and distribution of birds in a southern New England forest. Forest Ecology and Management 258:314-322.

Hagan, J. M., P. S. McKinley, A. L. Meehan, and S. L. Grove. 1997. Diversity and abundance of landbirds in a northeastern industrial forest. Journal of Wildlife Management 61:718735.

Harmon, M. E., and B. Marks. 2002. Effects of silvicultural practices on carbon stores in Douglas-fir-western hemlock forests in the Pacific Northwest, U.S.A.: results from a simulation model. Canadian Journal of Forest Research 32:863-877.

Hilt, D. E., and R. M. Teck. 1989. NE-TWIGS: an individualtree growth and yield projection system for the northeastern United States. Compiler 7:10-16.

Hobson, K. A., and J. Schieck. 1999. Changes in bird communities in boreal mixedwood forest: harvest and wildfire effects over 30 years. Ecological Applications 9:849-863.

Hoover, C. M., and S. A. Rebain. 2011. Forest carbon estimation using the Forest Vegetation Simulator: seven things you need to know. USDA Forest Service General Technical Report NRS-77. Northern Research Station, Newtown Square, Pennsylvania, USA.

Houghton, R. A. 2007. Balancing the global carbon budget. Annual Review of Earth and Planetary Sciences 35:313-347.

Hunter, W. C., D. A. Buehler, R. A. Canterbury, J. L. Confer, and P. B. Hamel. 2001. Conservation of disturbancedependent birds in eastern North America. Wildlife Society Bulletin 29:440-455.

Jackson, R. B., E. G. Jobbágy, R. Avissar, S. B. Roy, D. J. Barrett, C. W. Cook, K. A. Farley, D. C. le Maitre, B. A. McCarl, and B. C. Murray. 2005. Trading water for carbon with biological carbon sequestration. Science 310:1944-1947.

Jandl, R., M. Lindner, L. Vesterdal, B. Bauwens, R. Baritz, F. Hagedorn, D. W. Johnson, K. Minkkinen, and K. A. Byrne. 2007. How strongly can forest management influence soil carbon sequestration? Geoderma 137:253-268.

Jenkins, J. C., D. C. Chojnacky, L. S. Heath, and R. A. Birdsey. 2003. National-scale biomass estimators for United States tree species. Forest Science 49:12-35.

Kangas, J., and A. Kangas. 2005. Multiple criteria decision support in forest management - the approach, methods applied, and experiences gained. Forest Ecology and Management 207:133-143.

Keeton, W. S. 2007. Role of managed forestlands and models for sustainable forest management: perspectives from North America. George Wright Forum 24:38-53.

Keeton, W. S., C. E. Kraft, and D. R. Warren. 2007. Mature and old-growth riparian forests: structure, dynamics, and effects on Adirondack stream habitats. Ecological Applications 17:852-868.

Keeton, W. S., A. A. Whitman, G. G. McGee, and C. L. Goodale. 2011. Late-successional biomass development in northern hardwood-conifer forests of the northeastern United States. Forest Science 57:489-505.

Keller, J. K., M. E. Richmond, and C. R. Smith. 2003. An explanation of patterns of breeding bird species richness and density following clearcutting in northeastern USA forests. Forest Ecology and Management 174:541-564.

Kupfer, J. A., G. P. Malanson, and S. B. Franklin. 2006. Not seeing the ocean for the islands: the mediating influence of matrix-based processes on forest fragmentation effects. Global Ecology and Biogeography 15:8-20.

Lindenmayer, D. B., and J. F. Franklin. 2002. Conserving forest biodiversity: a comprehensive multiscaled approach. Island Press, Washington, D.C., USA.

MacFaden, S. W., and D. E. Capen. 2002. Avian habitat relationships at multiple scales in a New England forest. Forest Science 48:243-253.

MacKenzie, D. I., J. D. Nichols, G. B. Lachman, S. Droege, J. A. Royle, and C. A. Langtimm. 2002. Estimating site 
occupancy rates when detection probabilities are less than one. Ecology 83:2248-2255.

Mendoza, G. A., and H. Martins. 2006. Multi-criteria decision analysis in natural resource management: a critical review of methods and new modelling paradigms. Forest Ecology and Management 230:1-22.

Mitchell, B. R., and T. Donovan. 2008. Mob mentality: effect of a mobbing playback on avian detection probabilities during point count surveys. Open Ornithology Journal 1:819.

MRLC (Multi-Resolution Land Characteristics Consortium). 2001. National land cover database 2001. U.S. Geological Survey, MRLC Project, Sioux Falls, South Dakota, USA. http://www.mrlc.gov/

Nave, L. E., E. D. Vance, C. W. Swanston, and P. S. Curtis. 2010. Harvest impacts on soil carbon storage in temperate forests. Forest Ecology and Management 259:857-866.

Nunery, J. S., and W. S. Keeton. 2010. Forest carbon storage in the northeastern United States: net effects of harvesting frequency, post-harvest retention, and wood products. Forest Ecology and Management 259:1363-1375.

Perez-Garcia, J., B. Lippke, J. Comnick, and C. Manriquez. 2005. An assessment of carbon pools, storage, and wood products market substitution using life-cycle analysis results. Wood and Fiber Science 37:140-148.

Ray, D. G., M. R. Saunders, and R. S. Seymour. 2009a. Recent changes to the northeast variant of the Forest Vegetation Simulator and some basic strategies for improving model outputs. Northern Journal of Applied Forestry 26:31-34.

Ray, D. G., R. S. Seymour, N. A. Scott, and W. S. Keeton. 2009b. Mitigating climate change with managed forests: balancing expectations, opportunity, and risk. Journal of Forestry 107:50-51.

Rodewald, A. D., and R. H. Yahner. 2001. Influence of landscape composition on avian community structure and associated mechanisms. Ecology 82:3493-3504.

Ruddell, S., et al. 2007. The role for sustainably managed forests in climate change mitigation. Journal of Forestry 105:314-319.

Ryan, M. G., M. E. Harmon, R. A. Birdsey, C. P. Giardina, L. S. Heath, R. A. Houghton, R. B. Jackson, D. C. McKinley, J. F. Morrison, B. C. Murray, D. E. Pataki, and K. E. Skog. 2010. A synthesis of the science on forests and carbon for U.S. forests. Issues in Ecology 13:1-16.

SAS Institute. 2008. The SAS system version 9.2. SAS Institute, Cary, North Carolina, USA.

Schlossberg, S., and D. I. King. 2009. Postlogging succession and habitat usage of shrubland birds. Journal of Wildlife Management 73:226-231.

Schwenk, W. S., and T. M. Donovan. 2011. A multispecies framework for landscape conservation planning. Conservation Biology 25:1010-1021.
Seely, B., J. Nelson, R. Wells, B. Peter, M. Meitner, A. Anderson, H. Harshaw, S. Sheppard, F. L. Bunnell, H. Kimmins, and D. Harrison. 2004. The application of a hierarchical, decision-support system to evaluate multiobjective forest management strategies: a case study in northeastern British Columbia, Canada. Forest Ecology and Management 199:283-305.

Seidl, R., W. Rammer, D. Jäger, W. S. Currie, and M. J. Lexer. 2007. Assessing trade-offs between carbon sequestration and timber production within a framework of multi-purpose forestry in Austria. Forest Ecology and Management 248:64-79.

Smith, J. E., L. S. Heath, K. E. Skog, and R. A. Birdsey. 2006. Methods for calculating forest ecosystem and harvested carbon with standard estimates for forest types of the United States. USDA Forest Service General Technical Report NE343. Northeastern Research Station, Newtown Square, Pennsylvania, USA.

Swanson, M. E. 2009. Modeling the effects of alternative management strategies on forest carbon in the Nothofagus forests of Tierra del Fuego, Chile. Forest Ecology and Management 257:1740-1750.

Thompson, F. R., III, and D. E. Capen. 1988. Avian assemblages in seral stages of a Vermont forest. Journal of Wildlife Management 52:771-777.

Thompson, F. R., III, T. M. Donovan, R. M. DeGraaf, J. Faaborg, and S. K. Robinson. 2002. A multi-scale perspective of the effects of forest fragmentation on birds in eastern forests. Pages 8-19 in T. L. George and D. S. Dobkin, editors. Effects of habitat fragmentation on birds in western landscapes: Contrasts with paradigms from the eastern United States. Studies in Avian Biology Number 25. Cooper Ornithological Society, Camarillo, California, USA.

Twery, M. J., P. D. Knopp, S. A. Thomasma, H. M. Rauscher, D. E. Nute, W. D. Potter, F. Maier, J. Wang, M. Dass, H. Uchiyama, A. Glende, and R. E. Hoffman. 2005. NED-2: a decision support system for integrated forest ecosystem management. Computers and Electronics in Agriculture 49:24-43.

White, G. C., and K. P. Burnham. 1999. Program MARK: survival estimation from populations of marked animals. Bird Study 46(Supplement):120-139.

Wolfslehner, B., and R. Seidl. 2010. Harnessing ecosystem models and multi-criteria decision analysis for the support of forest management. Environmental Management 46:850861.

Yanai, R. D., W. S. Currie, and C. L. Goodale. 2003. Soil carbon dynamics after forest harvest: an ecosystem paradigm reconsidered. Ecosystems 6:197-212.

Yaussy, D. A. 2000. Comparison of an empirical forest growth and yield simulator and a forest gap simulator using actual 30 -year growth from two even-aged forests in Kentucky. Forest Ecology and Management 126:385-398.

\section{Supplemental Material}

\section{Appendix A}

Characteristics of 42 northern hardwood forest sites used in simulation modeling (Ecological Archives A022-085-A1).

\section{Appendix B}

Bird species and model results for species used in occupancy estimation (Ecological Archives A022-085-A2). 